\title{
Exploring the function of protein kinases in schistosomes: perspectives from the laboratory and from comparative genomics
}

\section{Anthony J. Walker*, Margarida Ressurreição and Rolf Rothermel}

Laboratory of Molecular Parasitology, School of Life Sciences, Kingston University, Kingston upon Thames, UK

Edited by:

Paul J. Brindley, The George

Washington University, USA

\section{Reviewed by:}

Amparo Latorre, University of Valencia, Spain

Paul J. Brindley, The George

Washington University, USA

*Correspondence:

Anthony J. Walker, Laboratory of Molecular Parasitology, School of Life Science, Kingston University, Penrhyn Road, Kingston upon Thames, Surrey, KT1 2EE, UK e-mail: t.walker@kingston.ac.uk
Eukaryotic protein kinases are well conserved through evolution. The genome of Schistosoma mansoni, which causes intestinal schistosomiasis, encodes over 250 putative protein kinases with all of the main eukaryotic groups represented. However, unraveling functional roles for these kinases is a considerable endeavor, particularly as protein kinases regulate multiple and sometimes overlapping cell and tissue functions in organisms. In this article, elucidating protein kinase signal transduction and function in schistosomes is considered from the perspective of the state-of-the-art methodologies used and comparative organismal biology, with a focus on current advances and future directions. Using the free-living nematode Caenorhabditis elegans as a comparator we predict roles for various schistosome protein kinases in processes vital for host invasion and successful parasitism such as sensory behavior, growth and development. It is anticipated that the characterization of schistosome protein kinases in the context of parasite function will catalyze cutting edge research into host-parasite interactions and will reveal new targets for developing drug interventions against human schistosomiasis.

Keywords: Schistosoma, kinome, Caenorhabditis elegans, kinase function, cell signaling, schistosomiasis

\section{PROTEIN KINASES AND SCHISTOSOMES-AN OVERVIEW}

Protein kinases are pivotal regulators of cellular function. When activated, these signaling enzymes phosphorylate transcription factors and other intracellular proteins leading to alteration in gene expression and/or other cellular behavior/activities. Elucidating functional roles for protein kinases in humans and other organisms such as Drosophila melanogaster and Caenorhabditis elegans has sometimes been challenging, particularly because protein kinase pathways can drive multiple functions and influence one another through cross talk (e.g., Krishna and Narang, 2008), the nature of which is often dependent upon "input" signal(s). This presents a conundrum when trying to characterize the functions of protein kinases in organisms that have only relatively recently entered the protein kinase research arena. Schistosomes, which are human blood parasites, arguably fall into this category. The importance of schistosomes, particularly Schistosoma mansoni, Schistosoma japonicum, and Schistosoma haematobium, is highlighted by the fact that they are responsible for causing the neglected tropical disease human schistosomiasis in over 200 million people worldwide (Steinmann et al., 2006).

The life cycle of these schistosomes is complex (Walker, 2011). Paired adult male and female worms living in the blood vessels of the human definitive host produce eggs that are excreted and hatch in fresh water releasing a miracidium that infects an aquatic intermediate host snail. In the snail the miracidium develops into a mother and then daughter sporocysts that produce cercariae; when released into water these cercariae search out and penetrate the skin of the human host. Each cercaria then transforms into a schistosomule which subsequently enters the circulation and develops into juvenile and then adult worms that pair to stimulate full maturation and egg laying. Considerable morphological and physiological differences exist between these separate schistosome life-cycle stages (Walker, 2011) and thus protein kinase function may be different in each individual life stage, adding a further layer of complexity to role characterization. Also, each life stage will intercept different "input" signals from its environment (Walker, 2011). Such signals will include: light and host-derived surface molecules in the free-living swimming stages (cercariae and miracidia); signaling molecules (e.g., growth factors) in the blood of the endoparasitic stages of both the snail (post-miracidia and mother/daughter sporocyst) and human (schistosomule and adult worm) host; and differences in osmolarity and/or temperature during infection of/release from the host. Furthermore, an immortalized schistosome cell line does not exist meaning that cellular experiments need to be conducted with whole schistosomes, fractions, or lysates thereof. Nevertheless, while challenging, defining roles for kinases in this fascinating parasite will be rewarding, enabling questions concerning cellular regulation, development and homeostasis, particularly during key life-stage transitions to be answered. Such research is also important to develop strategies focusing on drug-mediated kinase modulation in the parasite for therapeutic intervention.

Schistosoma mansoni, S. japonicum, and S. haematobium genome and transcriptome projects [e.g., ( $\mathrm{Hu}$ et al., 2003; Verjovski-Almeida et al., 2003; Berriman et al., 2009; 
The Schistosoma japonicum Genome Sequencing and Functional Analysis Consortium, 2009; Protasio et al., 2012; Young et al., 2012)] have provided crucial sequence and expression data to support research into schistosome signaling, and 252 putative protein kinase genes have been found in S. mansoni (Andrade et al., 2011). However, the number of protein kinases encoded by these genes remains unknown because of the possibility of alternative splicing. This phenomenon, which increases proteome complexity, likely provides over 900 protein kinases from 445 protein kinase genes in humans, with 209 genes encoding a single kinase (Anamika et al., 2009). Alternative splicing results in potentially diverse functions because protein kinase splice variants can possess different domain architectures (Anamika et al., 2009).

Schistosomes possess putative kinases from all eight main eukaryotic protein kinase groups (Andrade et al., 2011). They also possess upstream receptors and endogenous signaling molecules (Osman et al., 2006; Khayath et al., 2007; Berriman et al., 2009; Oliveira et al., 2009; The Schistosoma japonicum Genome Sequencing and Functional Analysis Consortium, 2009; Zamanian et al., 2011; Young et al., 2012). Importantly, in the context of host-parasite interactions, schistosomes have been shown to respond to human insulin (You et al., 2009), transforming growth factor (TGF)- $\beta 1$ (Osman et al., 2006), and tumor necrosis factor (TNF)- $\alpha$ (Oliveira et al., 2009), demonstrating that they can bind host signaling molecules and transduce input signals through intact pathways. Here, perspectives on unraveling kinase function in schistosomes are provided that stem from techniques in cell biology developed for other organisms and from comparative genomics using C. elegans as a model.

\section{SCHISTOSOME FUNCTIONAL KINOMICS—PERSPECTIVES FROM THE LABORATORY STUDYING ACTIVATED PROTEIN KINASES IN SCHISTOSOMES}

In our laboratory we have employed "smart" phospho-specific antibodies (Bonetta, 2005) to detect functionally activated protein kinases in life stages of S. mansoni. These antibodies, first produced by Cell Signaling Technology (CST; www.cellsignal. com) detect key phosphorylation sites (Tyr, Thr, or Ser) within the kinase that are critical for function. Although such antibodies are generated against phosphorylated human peptide sequences (typically 11-13 amino acids around the phosphorylation site), a number of such sequences are well conserved in kinases of invertebrates allowing certain antibodies to be used after careful validation. For example, anti-phospho antibodies against the mitogen-activated protein kinases (MAPKs) have been used widely in D. melanogaster and C. elegans (e.g., Gabay et al., 1997; You et al., 2006; Zhuang et al., 2006), and in snails (Plows et al., 2004, 2005) including B. glabrata, host to S. mansoni (Zahoor et al., 2008). In our approach (Ressurreição et al., 2011a) we first align the predicted Schistosoma kinase protein sequence (from www.GeneDB.org) with the orthologous sequence for the respective human kinase and search for conserved site(s) containing the important phosphorylation motif(s). We next select appropriate antibodies (e.g., from CST) and screen them using western blotting with extracts from untreated live parasites, and live parasites treated with an activator for the kinase in question (e.g., anisomycin for p38 MAPK). Increased immunoreactivity of the kinase from the exposed parasite samples provides the first indication of antibody suitability and of functional conservation of the phosphorylated site in schistosomes. Antibodies are then further validated before they are used routinely. This involves experiments such as inhibition assays to block upstream activators of the kinase or block direct kinase activation (Ludtmann et al., 2009), and if possible immunoprecipitation of the phosphorylated kinase followed by kinase assay. In principle, by raising antibodies against phospho-peptides identical to schistosome protein kinase sequences it is possible to produce schistosome-specific anti-phospho antibodies; however, this requires significant investment without knowing whether the phospho site is functionally active. A major benefit of using anti-phospho antibodies is that it is possible to study protein kinase activation with small quantities of protein (e.g., from $\sim 750$ schistosomules or one adult worm pair) using western blotting. While for some schistosome protein kinases activity has been determined using activity assays with conserved kinase substrates (Wiest et al., 1992; Swierczewski and Davies, 2009, 2010), the quantity of protein needed is usually considerably greater. A further benefit of phospho-specific antibodies is that they often work in immunohistochemistry allowing the exclusively activated kinase (rather than the just the protein) to be visualized within the intact parasite using fluorescencebased confocal laser scanning microscopy (Figure 1). For this we have coined the term "functional mapping" (De Saram et al., 2013) given that only the activated kinase is detected. This can be valuable to elucidate the apparent distribution of the activated kinase within the parasite enabling hypotheses concerning function to be formulated and subsequently tested (see below). To date we have employed anti-phospho antibodies in S. mansoni to explore the kinetics of protein kinase $\mathrm{C}(\mathrm{PKC})$ and $\mathrm{p} 38$ MAPK activation in miracidia during development to mother sporocysts (Ludtmann et al., 2009; Ressurreição et al., 2011b), to help demonstrate a role for p38 MAPK in miracidia motility (Ressurreição et al., 2011a), and to study protein kinase A (PKA) function in adult worms (De Saram et al., 2013). Our current research using anti-phospho antibodies is focusing further on these pathways and others [e.g., AKT and extracellular signalregulated kinase (ERK)] in cercariae, schistosomules, and adult worms.

We anticipate that the above tools will also help enable certain protein kinase-mediated signaling pathways to be delineated. Putative pathway maps have been constructed incorporating some schistosome protein kinases including MAPK pathways and others (Wang et al., 2006; Dissous et al., 2007; Berriman et al., 2009; Beckmann et al., 2010b). These are largely predicted using in silico data for schistosome pathway components, comparative mechanisms in vertebrates and, in some cases, interaction data from schistosomes obtained using valuable yeast two/threehybrid screening and immunoprecipitation experiments [e.g., for Src and syk tyrosine kinases and polo-like kinases (Plks) (Quack et al., 2009; Beckmann et al., 2010a,b; Long et al., 2012)]. However, experimental data delineating routes of pathway activation in schistosomes remain negligible and need to be expanded to develop functional pathway maps. 


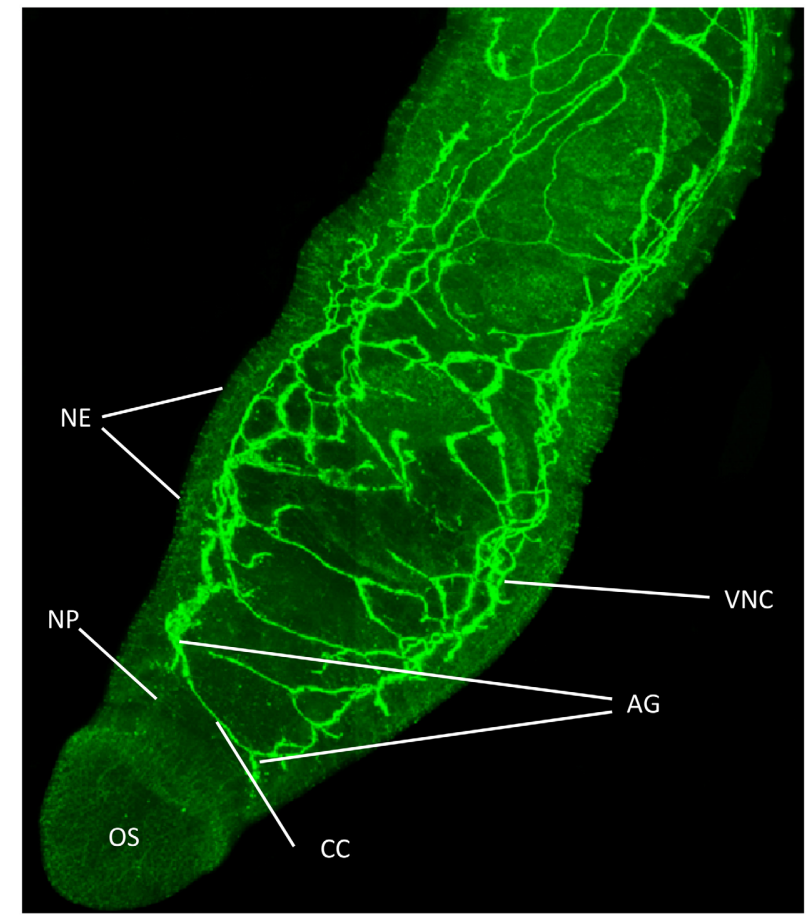

FIGURE 1 | Functional mapping of protein kinase A (PKA) in intact adult $\boldsymbol{S}$. mansoni. Male worms were fixed immediately after perfusion and stained with anti-phospho antibodies (green) to localize activated PKA. Image shows z-axis projection from intact worm in maximum pixel brightness mode. Intense staining reveals PKA activation particularly associated with the nervous system including in the ventral nerve cords (VNC), connecting cerebral commissures (CC), anterior ganglia (AG), complex nerve plexus (NP) associated with the oral sucker (OS) and nerve endings (NE) at the tegument surface. Bar $=100 \mu \mathrm{m}$. Adapted from De Saram et al. (2013).

DECIPHERING PROTEIN KINASE FUNCTION IN INTACT SCHISTOSOMES

Current strategies for interfering with protein kinases to elucidate function directly within schistosomes focus largely on pharmacological inhibition and conventional RNA interference (RNAi) by double stranded RNA. Probably the most controversial aspect of using kinase inhibitors is their potential to affect "non-target" kinases, particularly at high concentrations (Anastassiadis et al., 2011). However, when functional experiments are performed on intact parasites inhibitor IC50's have little meaning as their values are normally derived from cell-free or single-cell assays. To help mitigate possible non-target effects, careful selection of kinase inhibitors is needed, particularly as they often have different specificities. Sometimes sites of protein-inhibitor interaction have been mapped as illustrated by SB203580 and its target p38 MAPK (Gum et al., 1998; Wang et al., 1998). Such knowledge is valuable as it enables one to ascertain whether the critical residues are conserved in the schistosome kinase, as was found for S. japonicum p38 MAPK during our recent work (Ressurreição et al., 2011a). Moreover, performing inhibition experiments with subsequent kinase activity screening (see above) further validates inhibitor use. Experiments with inhibitors/activators have supported roles for kinases in S. mansoni including in: (1) miracidia/sporocysts, in which p38 MAPK (Ressurreição et al., 2011b) and PKC (Ludtmann et al., 2009) inhibition restrict and accelerate miracidia-to-mother sporocyst development, respectively, and activation of p38 MAPK attenuates miracidial ciliary motion (Ressurreição et al., 2011a); (2) cercariae and adult worms, in which PKA inhibition kills the parasite (Swierczewski and Davies, 2009, 2010); and (3) adult worms, in which PKA activation stimulates neuromuscular movement (De Saram et al., 2013), insulin and venus kinase receptor inhibition restricts feeding, egg-laying, and results in death (Vanderstraete et al., 2013), and SmTK4 and Plk inhibition suppresses gametogenesis (Beckmann et al., 2010a; Long et al., 2010). Moreover, inhibition and transcriptomic analysis have recently been used to identify a co-operative role for Src kinase and TGF $\beta$ in eggshell formation (Buro et al., 2013). By coupling outcomes of pharmacological experiments with in situ functional mapping (De Saram et al., 2013)/in-situ hybridization (Long et al., 2012), further confidence in terms of identified role can be achieved. Thus, inhibitor-based assays have an important place in functional schistosome kinomic research when used appropriately, and are particularly useful in short-term experiments as RNAi-mediated knockdown of a protein can take several days.

Conventional RNAi has become an invaluable tool for studying protein function in various life stages of Schistosoma species (Kalinna and Brindley, 2007; Stefanić et al., 2010; Rinaldi et al., 2011). This approach has been used to silence a large number of schistosome proteins including leucine aminopeptidase, involved in hatching of miracidia (Rinaldi et al., 2009), tetraspanins 1 and 2 that regulate tegument integrity (Tran et al., 2010), cathepsin B, important to schistosome growth (Correnti et al., 2005), and aquaporin, involved in excretion of metabolic waste across the tegument (Faghiri et al., 2010). Challenges with RNAi in schistosomes, however, remain and are considered elsewhere (Stefanić et al., 2010; Dalzell et al., 2012). These include the transient nature of RNAi, variable knockdown between individual parasites, and "knock-down" rather than "knock-out" of gene function, all of which can complicate phenotype analysis. To-date, there are relatively few reports of schistosome protein kinases being targeted by RNAi. These include knockdown of PKA, SmTK4, fibroblast growth factor receptor, TGF $\beta$ receptor II and $\mathrm{Ca}_{2}{ }^{+} /$calmodulin-dependent protein kinase II, found important for viability, gametogenesis, maintenance of neoblast-like cells, male-female reproductive development, and regulation of praziquantel induced calcium influx in adult worms, respectively (Osman et al., 2006; Swierczewski and Davies, 2009; Beckmann et al., 2010a; Collins et al., 2013; You et al., 2013). Importantly, the interconnected nature of kinase signaling is such that phenotypes caused by RNAi-mediated kinase depletion presumably reflect the aggregate biological consequence of disregulation of several pathways (Sopko and Andrews, 2008). Furthermore, phenotypes may also be masked by increased compensatory expression and subsequent activation of other isotypes and pathways in the face of suppression of any one isotype. Thus, although conventional RNAi is valuable for schistosome kinomics research, interpreting phenotype outcomes can be more challenging than for single gene/single function proteins. Nevertheless, in principle, as proposed for mammals (Moffat and Sabatini, 2006), it should 
be possible to perform high-throughput RNAi-based screening to delineate schistosome signaling pathways, using downstream phosphorylation events as "readouts" for depletion of "upstream" components such as kinases. Although an immortalized schistosome cell line might appear essential for such experiments, we consider progress could also be achieved using primary cell cultures derived from mechanically or enzymatically dissociated schistosome tissues, and possibly even totipotent stem cells recently identified in this parasite (Collins et al., 2013; Wang et al., 2013).

\section{SCHISTOSOME FUNCTIONAL KINOMICS-PERSPECTIVES AND PREDICTIONS FROM COMPARATIVE GENOMICS}

Given that protein kinases have been conserved through evolution, valuable insights into their possible functions in schistosomes can also be gleaned by considering roles for orthologous kinases in organisms in which functional genomics is more advanced. Here, selected $S$. mansoni protein kinases displaying orthology to protein kinases of the well-characterized C. elegans have been chosen (Table 1) to illustrate how comparative genomics can help build hypotheses for testing protein kinase function in schistosomes.

Caenorhabditis elegans dauer larvae exhibit distinct morphological and behavioral characteristics in response to environmental duress. AKT-1 and AKT-2, components of the insulin-like pathway, phosphorylate and inhibit the FoxO transcription factor DAF-16 (Paradis and Ruvkun, 1998; Hertweck et al., 2004) regulating dauer formation and lifespan $(\mathrm{Hu}, 2007)$, such that DAF-16/FoxO activation in the intestine affects lifespan whereas neuronal activity affects dauer formation (Libina et al., 2003). The orthologous S. mansoni Akt gene (Smp_073930) is particularly expressed in the schistosomules and adult worms (Table 1); it is therefore possible to predict that Akt may regulate lifespan in S. mansoni. Interestingly, Smp_172240 is orthologous for a c-Jun N-terminal kinase (JNK-1) in C. elegans, which acts together with the insulin-like pathway and converges with DAF16 to further promote lifespan regulation. In fact, $C$. elegans Jnk-1 mutants have reduced lifespan and increased tolerance to heat stress. JNK-1 modulates translocation of DAF-16 to the nucleus where it promotes expression of specific genes to combat environmental stress (Oh et al., 2005). Compared to cercariae, JNK-1 is more highly expressed in $3 \mathrm{~h}$ schistosomules (Table $\mathbf{1}$ ), which coincides with the considerable environmental change experienced by schistosomes upon entering the warm-blooded definitive host. The presence of Schistosoma insulin-like and JNK pathway components, vital to lifespan regulation in C. elegans, warrants investigations to decipher whether AKT and JNK regulate growth and development in schistosomes and whether these proteins co-operate in a similar manner. Thus, during our on-going investigations into AKT signaling in schistosomes we shall use the $C$. elegans knowledge base to build and test hypotheses concerning AKT function in different $S$. mansoni life stages.

Smp_065290, orthologous with CAM Kinase-1 in C. elegans and responsible for thermosensory behavior (Table 1), has raised expression in cercariae compared to $3 \mathrm{~h}$ schistosomules, consistent with cercariae being stimulated by a rising temperature gradients (Cohen et al., 1980). Although C. elegans CAMK-1 mutants display thermosensory defects, the mechanisms by which CAMK-1 operates remain to be characterized fully (Satterlee et al., 2004). Disruption of this gene in schistosomes would be interesting to revel whether it mediates host searching/cercarial penetration, possibly together with JNK-1 (orthologous to Smp_172240) that might play a role in thermosensation given its importance to thermotolerence in C. elegans (Table 1).

Schistosoma mansoni novel PKCe (Smp_131700; Table 1) is orthologous to $C$. elegans novel PKC-1 that plays a role in salt attraction (Adachi et al., 2010). Expression analysis (Table 1) suggests this gene is important in cercariae and early schistosomules. Increasing salinity promotes transformation of cercariae to schistosomules (Samueleson and Stein, 1989), thus, Smp_131700 provides an interesting target for phenotype disruption studies focusing on successful host infection by schistosomes. In C. elegans, PKC-1 is involved with ASE-right (ASER) neurons, which sense the $\mathrm{Cl}$ ion of $\mathrm{NaCl}$ (Adachi et al., 2010). ASER also express the guanylate cyclase receptor, gcy-22, essential in $\mathrm{Cl}$ ion sensing, and C. elegans gcy-22 mutants show impaired ability of ASER in response to varying salt concentrations (Ortiz et al., 2006). Interestingly, $\mathrm{PKC}-1$ has other roles in $C$. elegans including nose touch stimulation and locomotion with evidence suggesting it acts through the conserved ERK pathway (Hyde et al., 2011). It is thus tempting to predict a further role for S. mansoni PKC $\varepsilon$ in mechanosensation during contact of cercariae to host skin and in schistosome locomotion. Future immunolocalization studies may reveal PKCE in the nervous system of S. mansoni as in C. elegans.

Other examples illustrated in Table 1 include MAPK15, MEK1, casein kinase 1 (CK1), and vaccinia-related kinase (VRK), disruption of which in C. elegans is lethal to larvae, embryos, or both, and a G-protein coupled receptor kinase (GRK) that plays a role in chemotaxis, the hyperosmotic response and olfaction. The death-associated protein kinase (DAPK), expressed at high levels in all stages except $24 \mathrm{~h}$ schistosomules, plays an important role in epidermal and cuticle integrity and maintenance in C. elegans (Table 1). Given the importance of the schistosome tegument to host immune evasion and parasite survival (Van Hellemond et al., 2006), and the potential for similar effects in schistosomes, studies focusing on this kinase are warranted.

\section{SCHISTOSOME FUNCTIONAL KINOMICS—FUTURE PERSPECTIVES}

By integrating various approaches such as those detailed above and benefiting from emerging tools like schistosome transgenesis (Mann et al., 2011), it should be possible to unravel the complexity of protein kinase signaling in schistosomes. Certain protein kinases in schistosomes may ultimately be found to have roles comparable to those in other organisms including C. elegans, which can currently be used to generate functional hypotheses to test [see also further lethality predictions (Andrade et al., 2011)]. However, it is worth noting that common functionality may differ particularly as different organisms possess different complements of protein kinases and downstream target proteins, and because tissue expression may differ. To illustrate differences, in silico reconstruction of the S. mansoni and S. japonicum 


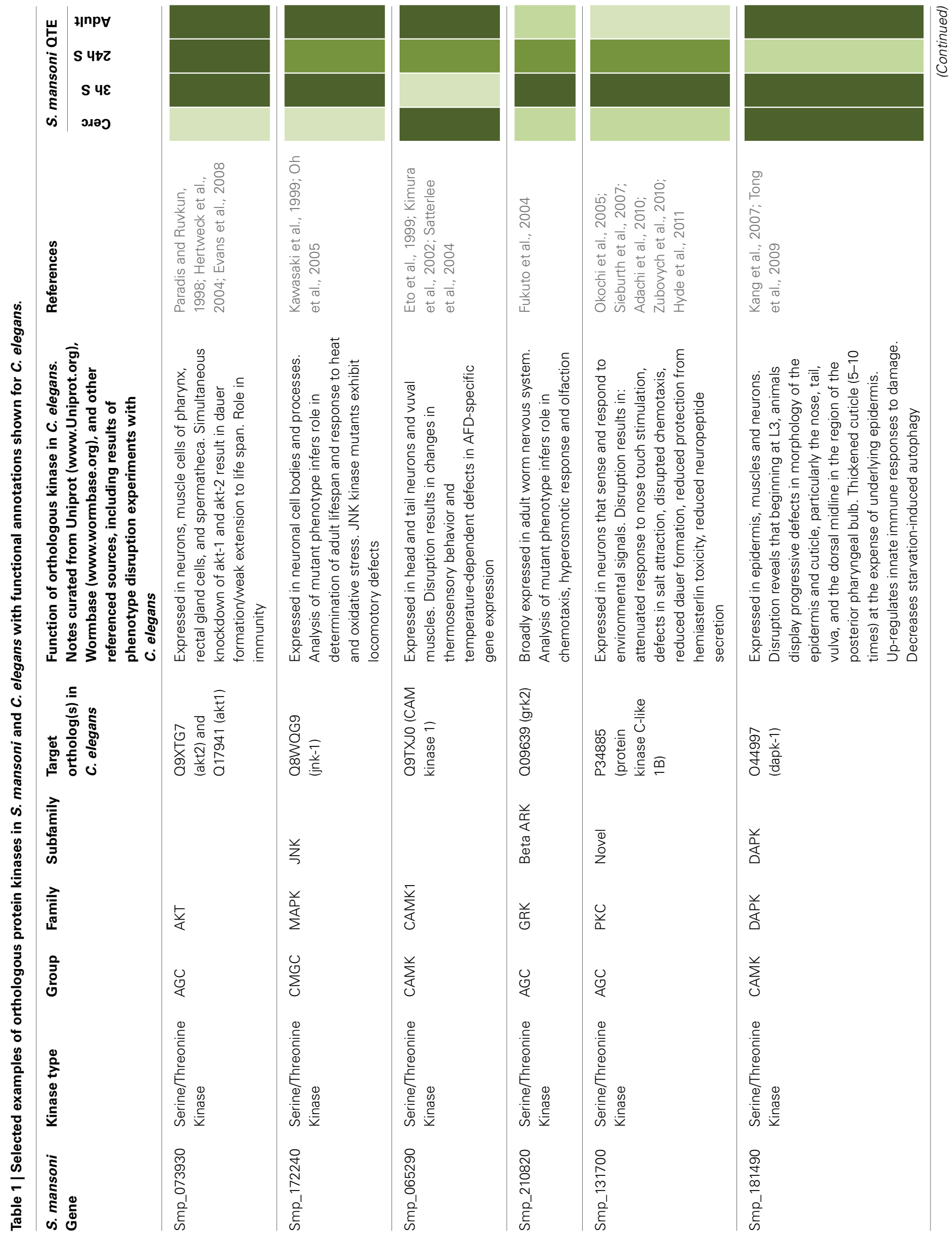




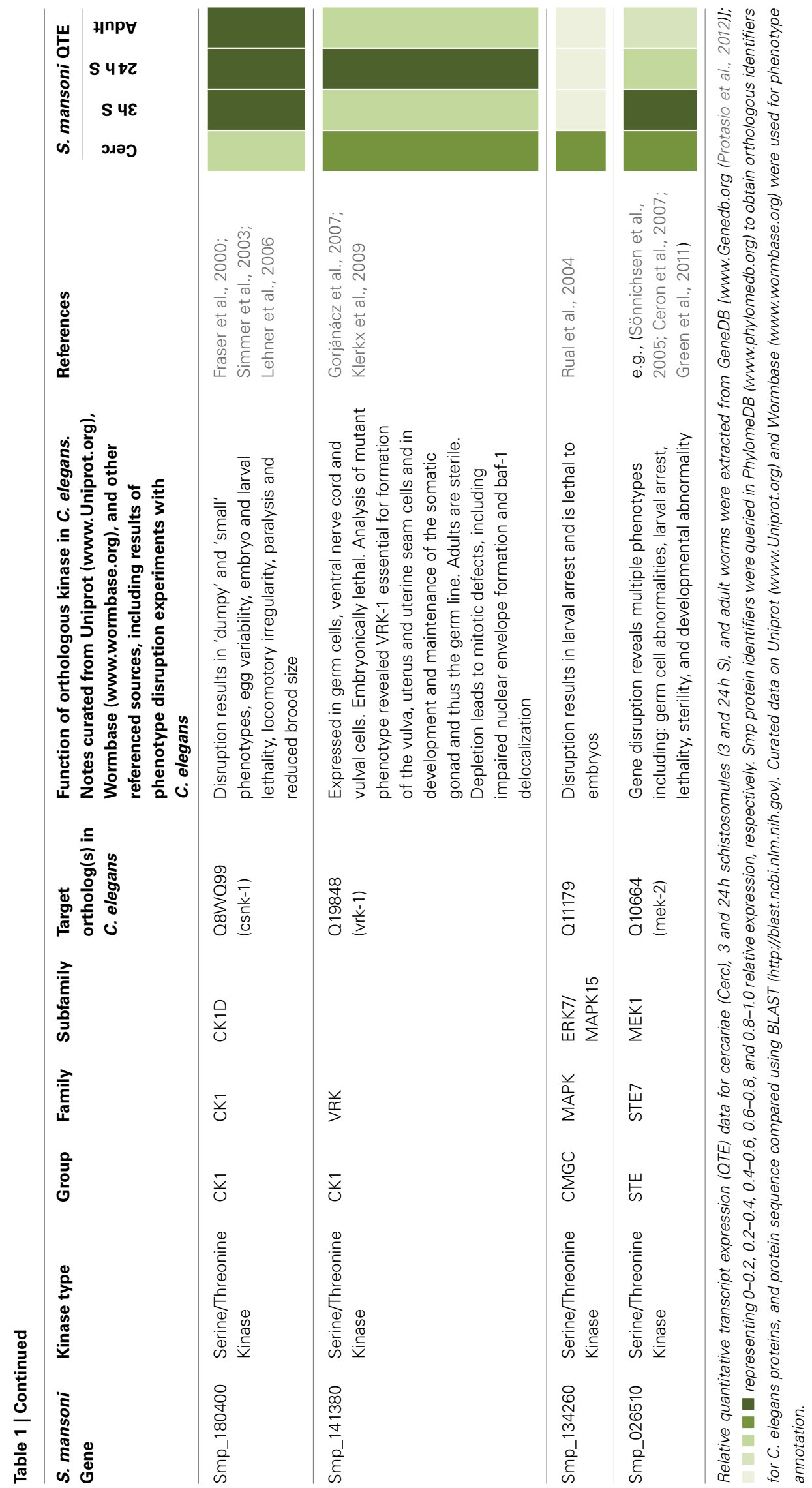


MAPK pathways (Wang et al., 2006; Berriman et al., 2009) shows that while many of the Schistosoma cytosolic signaling mechanisms are intact when compared to those of humans, the number of orthologous downstream transcription factors appear fewer, with members such as CREB, p53, c-Myc, and c-Jun strikingly absent. Thus, while hypothetical frameworks for kinase signaling in schistosomes may be built, they do need to be tested.

Schistosome protein kinase research is arguably in its infancy and many questions remain concerning the functional biology of these important enzymes in this parasite. To help address these issues, and to stimulate research on schistosome protein kinases, it is proposed here that key areas for on-going fundamental schistosome kinomic research should include:

(i) Identification of upstream activators and downstream targets of schistosome protein kinases to enable functional pathway characterization. To include consideration of "input" signals such as host growth factors;

(ii) Functional elucidation of protein kinases beyond the commonly used "gross" phenotypes (e.g., dead/alive, moving/not moving) often evaluated;

(iii) Consideration of all life stages to fully appreciate the complexity of protein kinase signaling in this parasite. This is important because outcomes from one life-stage may offer novel insights into cellular regulation in another life-stage.

By expanding research in the above areas, it should be ultimately possible to integrate fundamental research outcomes and develop a systems level understanding of protein kinase function in schistosomes. In doing so, opportunities will emerge along the way to consider individual kinases as targets for drug-mediated chemotherapy for schistosomiasis. This may include making use of drugs that are available/being considered for therapy of other diseases such as cancer [e.g., (Ali et al., 2009)], modification of such drugs, or development of new multi-species drugs that specifically target Schistosoma protein kinases.

\section{ACKNOWLEDGMENTS}

The authors would particularly like to acknowledge Paulu de Saram (for Figure 1) and Marthe Ludtmann for their work on schistosome protein kinases at Kingston University, and David Rollinson and Aidan Emery both long-term collaborators at the Natural History Museum, London for their insightful discussions.

\section{REFERENCES}

Adachi, T., Kunitomo, H., Tomioka, M., Ohno, H., Okochi, Y., Mori, I., et al. (2010). Reversal of salt preference is directed by the insulin/PI3K and Gq/PKC signaling in Caenorhabditis elegans. Genetics 186, 1309-1319. doi: 10.1534/genetics. 110.119768

Ali, A. S., Ali, S., El-Rayes, B. F., Philip, P. A., and Sarkar, F. H. (2009). Exploitation of protein kinase C: a useful target for cancer therapy. Cancer Treat. Rev. 35, 1-8. doi: 10.1016/j.ctrv.2008.07.006

Anamika, K., Garnier, N., and Srinivasan, N. (2009). Functional diversity of human protein kinase splice variants marks significant expansion of human kinome. BMC Genomics 10:622. doi: 10.1186/1471-2164-10-622

Anastassiadis, T., Deacon, S. W., Devarajan, K., Ma, H., and Peterson, J. R. (2011). Comprehensive assay of kinase catalytic activity reveals features of kinase inhibitor selectivity. Nat. Biotech. 29, 1039-1045. doi: 10.1038/ nbt.2017
Andrade, L. F., Nahum, L. A., Avelar, L. G. A., Silva, L. L., Zerlotini, A., Ruiz, J. C., et al. (2011). Eukaryotic protein kinases (ePKs) of the helminth parasite Schistosoma mansoni. BMC Genomics 12:215. doi: 10.1186/1471-2164-12-215

Beckmann, S., Buro, C., Dissous, C., Hirzmann, J., and Grevelding, C. G. (2010a). The Syk kinase SmTK4 of Schistosoma mansoni is involved in the regulation of spermatogenesis and oogenesis. PLoS Pathog. 6:e1000769. doi: 10.1371/journal.ppat.1000769

Beckmann, S., Quack, T., Burmeister, C., Buro, C., Long, T., Dissous, C., et al. (2010b). Schistosoma mansoni: signal transduction processes during the development of the reproductive organs. Parasitology 137, 497-520. doi: 10.1017/S0031182010000053

Berriman, M., Haas, B. J., LoVerde, P. T., Wilson, R. A., Dillon, G. P., Cerqueira, G. C., et al. (2009). The genome of the blood fluke Schistosoma mansoni. Nature 460, 352-358. doi: 10.1038/nature08160

Bonetta, L. (2005). Probing the kinome. Nat. Methods 2, 225-232. doi: 10.1038/nmeth0305-225

Buro, C., Oliveira, K. C., Lu, Z., Leutner, S., Beckmann, S., Dissous, C., et al. (2013). Transcriptome analyses of inhibitor-treated schistosome females provide evidence for cooperating Src-kinase and TGF $\beta$ receptor pathways controlling mitosis and eggshell formation. PLoS Pathog. 9:e1003448. doi: 10.1371/journal.ppat. 1003448

Ceron, J., Rual, J.-F., Chandra, A., Dupuy, D., Vidal, M., and van den Heuvel, S. (2007). Large-scale RNAi screens identify novel genes that interact with the C. elegans retinoblastoma pathway as well as splicing-related components with synMuv B activity. BMC Dev. Biol. 7:30. doi: 10.1186/1471-213X-7-30

Cohen, L., Neimark, H., and Eveland, L. (1980). Schistosoma mansoni: response of cercariae to a thermal gradient. J. Parasitol. 66, 362-364.

Collins, J. J., Wang, B., Lambrus, B. G., Tharp, M. E., Iyer, H., and Newmark, P. A. (2013). Adult somatic stem cells in the human parasite Schistosoma mansoni. Nature 494, 476-479. doi: 10.1038/nature11924

Correnti, J. M., Brindley, P. J., and Pearce, E. J. (2005). Long-term suppression of cathepsin B levels by RNA interference retards schistosome growth. Mol. Biochem. Parasitol. 143, 209-215. doi: 10.1016/j.molbiopara.2005.06.007

Dalzell, J. J., Warnock, N. D., McVeigh, P., Marks, N. J., Mousley, A., Atkinson, L., et al. (2012). Considering RNAi experimental design in parasitic helminths. Parasitology 139, 589-604. doi: 10.1017/S0031182011001946

De Saram, P. S. R., Ressurreição, M., Davies, A. J., Rollinson, D., Emery, A. M., and Walker, A. J. (2013). Functional mapping of protein kinase A reveals its importance in adult Schistosoma mansoni motor activity. PLoS Negl. Trop. Dis. 7:e1988. doi: 10.1371/journal.pntd.0001988

Dissous, C., Ahier, A., and Khayath, N. (2007). Protein tyrosine kinases as new potential targets against human schistosomiasis. BioEssays 29, 1281-1288. doi: 10.1002/bies.20662

Eto, K., Takahashi, N., Kimura, Y., Masuho, Y., Arai, K., Muramatsu, M. A., et al. (1999). Ca(2+)/Calmodulin-dependent protein kinase cascade in Caenorhabditis elegans. Implication in transcriptional activation. J. Biol. Chem. 274, 22556-22562. doi: 10.1074/jbc.274.32.22556

Evans, E. A., Chen, W. C., and Tan, M.-W. (2008). The DAF-2 insulin-like signaling pathway independently regulates aging and immunity in C. elegans. Aging Cell 7, 879-893. doi: 10.1111/j.1474-9726.2008.00435.x

Faghiri, Z., Camargo, S. M. R., Huggel, K., Forster, I. C., Ndegwa, D., Verrey, F., et al. (2010). The tegument of the human parasitic worm Schistosoma mansoni as an excretory organ: the surface aquaporin SmAQP is a lactate transporter. PLoS ONE 5:e10451. doi: 10.1371/journal.pone.0010451

Fraser, A. G., Kamath, R. S., Zipperlen, P., Martinez-Campos, M., Sohrmann, M., and Ahringer, J. (2000). Functional genomic analysis of C. elegans chromosome I by systematic RNA interference. Nature 408, 325-330. doi: 10.1038/35042517

Fukuto, H. S., Ferkey, D. M., Apicella, A. J., Lans, H., Sharmeen, T., Chen, W., et al. (2004). G protein-coupled receptor kinase function is essential for chemosensation in C. elegans. Neuron 42, 581-593. doi: 10.1016/S0896-6273(04)00252-1

Gabay, L., Seger, R., and Shilo, B. Z. (1997). MAP kinase in situ activation atlas during Drosophila embryogenesis. Development 124, 3535-3541.

Gorjánácz, M., Klerkx, E. P. F., Galy, V., Santarella, R., López-Iglesias, C., Askjaer, P., et al. (2007). Caenorhabditis elegans BAF-1 and its kinase VRK-1 participate directly in post-mitotic nuclear envelope assembly. EMBO J. 26, 132-143. doi: 10.1038/sj.emboj.7601470

Green, R. A., Kao, H.-L., Audhya, A., Arur, S., Mayers, J. R., Fridolfsson, H. N., et al. (2011). A high-resolution C. elegans essential gene network based on phenotypic profiling of a complex tissue. Cell 145, 470-482. doi: 10.1016/j.cell.2011.03.037 
Gum, R. J., McLaughlin, M. M., Kumar, S., Wang, Z., Bower, M. J., Lee, J. C., et al. (1998). Acquisition of sensitivity of stress-activated protein kinases to the p38 inhibitor, SB 203580, by alteration of one or more amino acids within the ATP binding pocket. J. Biol. Chem. 273, 15605-15610. doi: 10.1074/jbc.273.25.15605

Hertweck, M., Göbel, C., and Baumeister, R. (2004). C. elegans SGK-1 is the critical component in the Akt/PKB kinase complex to control stress response and life span. Dev. Cell 6, 577-588. doi: 10.1016/S1534-5807(04)00095-4

Hu, P. J. (2007). Dauer. WormBook 1-19. doi: 10.1895/wormbook.1.144.1

Hu, W., Yan, Q., Shen, D.-K., Liu, F., Zhu, Z.-D., Song, H.-D., et al. (2003). Evolutionary and biomedical implications of a Schistosoma japonicum complementary DNA resource. Nat. Genet. 35, 139-147. doi: 10.1038/ng1236

Hyde, R., Corkins, M. E., Somers, G. A., and Hart, A. C. (2011). PKC-1 acts with the ERK MAPK signaling pathway to regulate Caenorhabditis elegans mechanosensory response. Genes Brain Behav. 10, 286-298. doi: 10.1111/j.1601183X.2010.00667.x

Kalinna, B. H., and Brindley, P. J. (2007). Manipulating the manipulators: advances in parasitic helminth transgenesis and RNAi. Trends Parasitol. 23, 197-204. doi: 10.1016/j.pt.2007.03.007

Kang, C., You, Y., and Avery, L. (2007). Dual roles of autophagy in the survival of Caenorhabditis elegans during starvation. Genes Dev. 21, 2161-2171. doi: $10.1101 /$ gad.1573107

Kawasaki, M., Hisamoto, N., Iino, Y., Yamamoto, M., Ninomiya-Tsuji, J., and Matsumoto, K. (1999). A Caenorhabditis elegans JNK signal transduction pathway regulates coordinated movement via type-D GABAergic motor neurons. EMBO J. 18, 3604-3615. doi: 10.1093/emboj/18.13.3604

Khayath, N., Vicogne, J., Ahier, A., BenYounes, A., Konrad, C., Trolet, J., et al. (2007). Diversification of the insulin receptor family in the helminth parasite Schistosoma mansoni. FEBS J. 274, 659-676. doi: 10.1111/j.17424658.2006.05610.x

Kimura, Y., Corcoran, E. E., Eto, K., Gengyo-Ando, K., Muramatsu, M.-A., Kobayashi, R., et al. (2002). A CaMK cascade activates CRE-mediated transcription in neurons of Caenorhabditis elegans. EMBO Rep. 3, 962-966. doi: 10.1093/embo-reports/kvf191

Klerkx, E. P. F., Alarcón, P., Waters, K., Reinke, V., Sternberg, P. W., and Askjaer, P. (2009). Protein kinase VRK-1 regulates cell invasion and EGL17/FGF signaling in Caenorhabditis elegans. Dev. Biol. 335, 12-21. doi: 10.1016/j.ydbio.2009.08.007

Krishna, M., and Narang, H. (2008). The complexity of mitogen-activated protein kinases (MAPKs) made simple. Cell. Mol. Life Sci. 65, 3525-3544. doi: 10.1007/s00018-008-8170-7

Lehner, B., Calixto, A., Crombie, C., Tischler, J., Fortunato, A., Chalfie, M., et al. (2006). Loss of LIN-35, the Caenorhabditis elegans ortholog of the tumor suppressor p105Rb, results in enhanced RNA interference. Genome Biol. 7:R4. doi: 10.1186/gb-2006-7-1-r4

Libina, N., Berman, J. R., and Kenyon, C. (2003). Tissue-specific activities of C. elegans DAF-16 in the regulation of lifespan. Cell 115, 489-502. doi: 10.1016/S0092-8674(03)00889-4

Long, T., Cailliau, K., Beckmann, S., Browaeys, E., Trolet, J., Grevelding, C. G., et al. (2010). Schistosoma mansoni polo-like kinase 1: a mitotic kinase with key functions in parasite reproduction. Int. J. Parasitol. 40, 1075-1086. doi: 10.1016/j.ijpara.2010.03.002

Long, T., Vanderstraete, M., Cailliau, K., Morel, M., Lescuyer, A., Gouignard, N., et al. (2012). SmSak, the second polo-like kinase of the helminth parasite Schistosoma mansoni: conserved and unexpected roles in meiosis. PLoS ONE 7:e40045. doi: 10.1371/journal.pone.0040045

Ludtmann, M. H. R., Rollinson, D., Emery, A. M., and Walker, A. J. (2009). Protein kinase $\mathrm{C}$ signalling during miracidium to mother sporocyst development in the helminth parasite, Schistosoma mansoni. Int. J. Parasitol. 39, 1223-1233. doi: 10.1016/j.ijpara.2009.04.002

Mann, V. H., Suttiprapa, S., Rinaldi, G., and Brindley, P. J. (2011). Establishing transgenic schistosomes. PLoS Negl. Trop. Dis. 5:e1230. doi: 10.1371/journal.pntd.0001230

Moffat, J., and Sabatini, D. M. (2006). Building mammalian signalling pathways with RNAi screens. Nat. Rev. Mol. Cell Biol. 7, 177-187. doi: 10.1038/nrm1860

Oh, S. W., Mukhopadhyay, A., Svrzikapa, N., Jiang, F., Davis, R. J., and Tissenbaum, H. A. (2005). JNK regulates lifespan in Caenorhabditis elegans by modulating nuclear translocation of forkhead transcription factor/DAF-16. Proc. Natl. Acad. Sci. U.S.A. 102, 4494-4499. doi: 10.1073/pnas.0500749102
Okochi, Y., Kimura, K. D., Ohta, A., and Mori, I. (2005). Diverse regulation of sensory signaling by C. elegans nPKC-epsilon/eta TTX-4. EMBO J. 24, 2127-2137. doi: 10.1038/sj.emboj.7600697

Oliveira, K. C., Carvalho, M. L. P., Venancio, T. M., Miyasato, P. A., Kawano, T., DeMarco, R., et al. (2009). Identification of the Schistosoma mansoni TNFalpha receptor gene and the effect of human TNF-alpha on the parasite gene expression profile. PLoS Negl. Trop. Dis. 3:e556. doi: 10.1371/journal.pntd. 0000556

Ortiz, C. O., Etchberger, J. F., Posy, S. L., Frøkjaer-Jensen, C., Lockery, S., Honig, B., et al. (2006). Searching for neuronal left/right asymmetry: genomewide analysis of nematode receptor-type guanylyl cyclases. Genetics 173, 131-149. doi: 10.1534/genetics.106.055749

Osman, A., Niles, E. G., Verjovski-Almeida, S., and LoVerde, P. T. (2006). Schistosoma mansoni TGF-beta receptor II: role in host ligand-induced regulation of a schistosome target gene. PLoS Pathog. 2:e54. doi: 10.1371/journal.ppat.0020054

Paradis, S., and Ruvkun, G. (1998). Caenorhabditis elegans Akt/PKB transduces insulin receptor-like signals from AGE-1 PI3 kinase to the DAF-16 transcription factor. Genes Dev. 12, 2488-2498. doi: 10.1101/gad.12.16.2488

Plows, L. D., Cook, R. T., Davies, A. J., and Walker, A. J. (2004). Activation of extracellular-signal regulated kinase is required for phagocytosis by Lymnaea stagnalis haemocytes. Biochim. Biophys. Acta 1692, 25-33. doi: 10.1016/j.bbamcr.2004.03.002

Plows, L. D., Cook, R. T., Davies, A. J., and Walker, A. J. (2005). Carbohydrates that mimic schistosome surface coat components affect ERK and PKC signalling in Lymnaea stagnalis haemocytes. Int. J. Parasitol. 35, 293-302. doi: 10.1016/j.ijpara.2004.11.012

Protasio, A. V., Tsai, I. J., Babbage, A., Nichol, S., Hunt, M., Aslett, M. A., et al. (2012). A systematically improved high quality genome and transcriptome of the human blood fluke Schistosoma mansoni. PLoS Negl. Trop. Dis. 6:e1455. doi: 10.1371/journal.pntd.0001455

Quack, T., Knobloch, J., Beckmann, S., Vicogne, J., Dissous, C., and Grevelding, C. G. (2009). The formin-homology protein SmDia interacts with the Src kinase SmTK and the GTPase SmRhol in the gonads of Schistosoma mansoni. PLoS ONE 4:e6998. doi: 10.1371/journal.pone.0006998

Ressurreição, M., Rollinson, D., Emery, A. M., and Walker, A. J. (2011a). A role for p38 MAPK in the regulation of ciliary motion in a eukaryote. BMC Cell Biol. 12:6. doi: 10.1186/1471-2121-12-6

Ressurreição, M., Rollinson, D., Emery, A. M., and Walker, A. J. (2011b). A role for p38 mitogen-activated protein kinase in early post-embryonic development of Schistosoma mansoni. Mol. Biochem. Parasitol. 180, 51-55. doi: 10.1016/j.molbiopara.2011.07.002

Rinaldi, G., Morales, M. E., Alrefaei, Y. N., Cancela, M., Castillo, E., Dalton, J. P., et al. (2009). RNA interference targeting leucine aminopeptidase blocks hatching of Schistosoma mansoni eggs. Mol. Biochem. Parasitol. 167, 118-126. doi: 10.1016/j.molbiopara.2009.05.002

Rinaldi, G., Okatcha, T. I., Popratiloff, A., Ayuk, M. A., Suttiprapa, S., Mann, V. H., et al. (2011). Genetic manipulation of Schistosoma haematobium, the neglected schistosome. PLoS Negl. Trop. Dis. 5:e1348. doi: 10.1371/journal.pntd. 0001348

Rual, J.-F., Ceron, J., Koreth, J., Hao, T., Nicot, A.-S., Hirozane-Kishikawa, T., et al. (2004). Toward improving Caenorhabditis elegans phenome mapping with an ORFeome-based RNAi library. Genome Res. 14, 2162-2168. doi: 10.1101/gr.2505604

Samueleson, J. C., and Stein, L. D. (1989). Schistosoma mansoni: increasing saline concentration signals cercariae to transform to schistosomula. Exp. Parasitol. 69, 23-29.

Satterlee, J. S., Ryu, W. S., and Sengupta, P. (2004). The CMK-1 CaMKI and the TAX-4 Cyclic nucleotide-gated channel regulate thermosensory neuron gene expression and function in C. elegans. Curr. Biol. 14, 62-68. doi: 10.1016/j.cub.2003.12.030

Sieburth, D., Madison, J. M., and Kaplan, J. M. (2007). PKC-1 regulates secretion of neuropeptides. Nat. Neurosci. 10, 49-57. doi: 10.1038/ nn 1810

Simmer, F., Moorman, C., van der Linden, A. M., Kuijk, E., van den Berghe, P. V. E., Kamath, R. S., et al. (2003). Genome-wide RNAi of C. elegans using the hypersensitive rrf-3 strain reveals novel gene functions. PLoS Biol. 1:e12. doi: 10.1371/journal.pbio.0000012 
Sönnichsen, B., Koski, L. B., Walsh, A., Marschall, P., Neumann, B., Brehm, M., et al. (2005). Full-genome RNAi profiling of early embryogenesis in Caenorhabditis elegans. Nature 434, 462-469. doi: 10.1038/nature03353

Sopko, R., and Andrews, B. J. (2008). Linking the kinome and phosphorylomea comprehensive review of approaches to find kinase targets. Mol. Biosyst. 4, 920-933. doi: 10.1039/b801724g

Stefanić, S., Dvořák, J., Horn, M., Braschi, S., Sojka, D., Ruelas, D. S., et al. (2010). RNA interference in Schistosoma mansoni schistosomula: selectivity, sensitivity and operation for larger-scale screening. PLoS Negl. Trop. Dis. 4:e850. doi: 10.1371/journal.pntd.0000850

Steinmann, P., Keiser, J., Bos, R., Tanner, M., and Utzinger, J. (2006). Schistosomiasis and water resources development: systematic review, metaanalysis, and estimates of people at risk. Lancet Infect. Dis. 6, 411-425. doi: 10.1016/S1473-3099(06)70521-7

Swierczewski, B. E., and Davies, S. J. (2009). A schistosome cAMP-dependent protein kinase catalytic subunit is essential for parasite viability. PLoS Negl. Trop. Dis. 3:e505. doi: 10.1371/journal.pntd.0000505

Swierczewski, B. E., and Davies, S. J. (2010). Developmental regulation of protein kinase A expression and activity in Schistosoma mansoni. Int. J. Parasitol. 40, 929-935. doi: 10.1016/j.ijpara.2010.01.001

The Schistosoma japonicum Genome Sequencing and Functional Analysis Consortium (2009). The Schistosoma japonicum genome reveals features of host-parasite interplay. Nature 460, 345-351. doi: 10.1038/nature08140

Tong, A., Lynn, G., Ngo, V., Wong, D., Moseley, S. L., Ewbank, J. J., et al. (2009). Negative regulation of Caenorhabditis elegans epidermal damage responses by death-associated protein kinase. Proc. Natl. Acad. Sci. U.S.A. 106, 1457-1461. doi: 10.1073/pnas.0809339106

Tran, M. H., Freitas, T. C., Cooper, L., Gaze, S., Gatton, M. L., Jones, M. K., et al. (2010). Suppression of mRNAs encoding tegument tetraspanins from Schistosoma mansoni results in impaired tegument turnover. PLoS Pathog. 6:e1000840. doi: 10.1371/journal.ppat.1000840

Vanderstraete, M., Gouignard, N., Cailliau, K., Morel, M., Lancelot, J., Bodart, J.-F., et al. (2013). Dual targeting of insulin and venus kinase receptors of Schistosoma mansoni for novel anti-schistosome therapy. PLoS Negl. Trop. Dis. 7:e2226. doi: 10.1371/journal.pntd.0002226

Van Hellemond, J. J., Retra, K., Brouwers, J. F. H. M., van Balkom, B. W. M., Yazdanbakhsh, M., Shoemaker, C. B., et al. (2006). Functions of the tegument of schistosomes: clues from the proteome and lipidome. Int. J. Parasitol. 36, 691-699. doi: 10.1016/j.ijpara.2006.01.007

Verjovski-Almeida, S., DeMarco, R., Martins, E. A. L., Guimarães, P. E. M., Ojopi, E. P. B., Paquola, A. C. M., et al. (2003). Transcriptome analysis of the acoelomate human parasite Schistosoma mansoni. Nat. Genet. 35, 148-157. doi: $10.1038 / \mathrm{ng} 1237$

Walker, A. J. (2011). Insights into the functional biology of schistosomes. Parasit. Vectors 4:203. doi: 10.1186/1756-3305-4-203

Wang, B., Collins, J. J., and Newmark, P. A. (2013). Functional genomic characterization of neoblast-like stem cells in larval Schistosoma mansoni. Elife 2:e00768. doi: 10.7554/eLife.00768

Wang, L., Yang, Z., Li, Y., Yu, F., Brindley, P. J., McManus, D. P., et al. (2006). Reconstruction and in silico analysis of the MAPK signaling pathways in the human blood fluke, Schistosoma japonicum. FEBS Lett. 580, 3677-3686. doi: 10.1016/j.febslet.2006.05.055
Wang, Z., Canagarajah, B. J., Boehm, J. C., Kassisà, S., Cobb, M. H., Young, P. R., et al. (1998). Structural basis of inhibitor selectivity in MAP kinases. Structure $6,1117-1128$.

Wiest, P. M., Burnham, D. C., Olds, G. R., and Bowen, W. D. (1992). Developmental expression of protein kinase C activity in Schistosoma mansoni. Am. J. Trop. Med. Hyg. 46, 358-365.

You, H., McManus, D. P., Hu, W., Smout, M. J., Brindley, P. J., and Gobert, G. N. (2013). Transcriptional responses of in vivo praziquantel exposure in schistosomes identifies a functional role for calcium signalling pathway member CamKII. PLoS Pathog. 9:e1003254. doi: 10.1371/journal.ppat.1003254

You, H., Zhang, W., Moertel, L., McManus, D. P., and Gobert, G. N. (2009). Transcriptional profiles of adult male and female Schistosoma japonicum in response to insulin reveal increased expression of genes involved in growth and development. Int. J. Parasitol. 39, 1551-1559. doi: 10.1016/j.ijpara.2009.06.006

You, Y., Kim, J., Cobb, M., and Avery, L. (2006). Starvation activates MAP kinase through the muscarinic acetylcholine pathway in Caenorhabditis elegans pharynx. Cell Metab. 3, 237-245. doi: 10.1016/j.cmet.2006.02.012

Young, N. D., Jex, A. R., Li, B., Liu, S., Yang, L., Xiong, Z., et al. (2012). Wholegenome sequence of Schistosoma haematobium. Nat. Genet. 44, 221-225. doi: 10.1038/ng.1065

Zahoor, Z., Davies, A. J., Kirk, R. S., Rollinson, D., and Walker, A. J. (2008). Disruption of ERK signalling in Biomphalaria glabrata defence cells by Schistosoma mansoni: implications for parasite survival in the snail host. Dev. Comp. Immunol. 32, 1561-1571. doi: 10.1016/j.dci.2008.05.014

Zamanian, M., Kimber, M. J., McVeigh, P., Carlson, S. A., Maule, A. G., and Day, T. A. (2011). The repertoire of $G$ protein-coupled receptors in the human parasite Schistosoma mansoni and the model organism Schmidtea mediterranea. BMC Genomics 12:596. doi: 10.1186/1471-2164-12-596

Zhuang, Z.-H., Zhou, Y., Yu, M.-C., Silverman, N., and Ge, B.-X. (2006). Regulation of Drosophila p38 activation by specific MAP2 kinase and MAP3 kinase in response to different stimuli. Cell. Signal. 18, 441-448. doi: 10.1016/j.cellsig.2005.05.013

Zubovych, I. O., Straud, S., and Roth, M. G. (2010). Mitochondrial dysfunction confers resistance to multiple drugs in Caenorhabditis elegans. Mol. Biol. Cell 21, 956-969. doi: 10.1091/mbc.E09-08-0673

Conflict of Interest Statement: The authors declare that the research was conducted in the absence of any commercial or financial relationships that could be construed as a potential conflict of interest.

Received: 11 February 2014; accepted: 30 June 2014; published online: 31 July 2014. Citation: Walker AJ, Ressurreição M and Rothermel R (2014) Exploring the function of protein kinases in schistosomes: perspectives from the laboratory and from comparative genomics. Front. Genet. 5:229. doi: 10.3389/fgene.2014.00229

This article was submitted to Evolutionary and Genomic Microbiology, a section of the journal Frontiers in Genetics.

Copyright (c) 2014 Walker, Ressurreição and Rothermel. This is an open-access article distributed under the terms of the Creative Commons Attribution License (CC BY). The use, distribution or reproduction in other forums is permitted, provided the original author(s) or licensor are credited and that the original publication in this journal is cited, in accordance with accepted academic practice. No use, distribution or reproduction is permitted which does not comply with these terms. 